Research Article

\title{
Study on Dynamic Mechanical Properties of Full Tailings Cemented Backfilling Impacted by Cement-Sand Ratio
}

\author{
Shan Yang $\mathbb{D},{ }^{1}$ Zhiyong Zhou $\mathbb{D},{ }^{1}$ Yifei Zhao $\mathbb{D}^{1},{ }^{1}$ and Wei Yang $\mathbb{D}{ }^{1,2}$ \\ ${ }^{1}$ School of Resources and Safety Engineering, Central South University, Changsha 410083, Hunan, China \\ ${ }^{2}$ Jiangxi Copper Corporation, Nanchang 330029, Jiangxi, China \\ Correspondence should be addressed to Zhiyong Zhou; csuzzy@csu.edu.cn and Yifei Zhao; 1206102513@qq.com
}

Received 4 June 2018; Accepted 6 August 2018; Published 23 September 2018

Academic Editor: Zhongwei Chen

Copyright (c) 2018 Shan Yang et al. This is an open access article distributed under the Creative Commons Attribution License, which permits unrestricted use, distribution, and reproduction in any medium, provided the original work is properly cited.

\begin{abstract}
In order to study the effect of cement-sand ratio on the dynamic mechanical properties of the full tailings cemented backfilling, three sets of full tailings cemented backfilling specimens with different cement-sand ratios were prefabricated. The uniaxial impact of the prefabricated specimens was performed by the $\Phi 50 \mathrm{~mm}$ SHPB test system. Test results showed that full tailings cemented backfilling had strong reflection and damping effects on elastic wave propagation. At lower strain rates, specimens presented strength hardening, and at higher strain rates, the test specimens presented rapid-softening strength; the strength-hardened specimen reached the peak stress at $40 \mu \mathrm{s}$, and the softening specimen reached the peak stress at about $18 \mu \mathrm{s}$; with the increase of strain rate, dynamic compressive strength, growth factor of dynamic strength, peak strain, and dynamic-static strain ratio of specimens increased totally. When the cement-sand ratio increased, ultimate dynamic compressive strength, limit dynamic strength growth factor, and ultimate peak strain of the specimen were higher; at the same strain rate, with the increase of cement content, the dynamic compressive strength, dynamic strength growth factor, and dynamic-static strain ratio of the test piece all decreased. The failure mode of the specimen was crushing failure. Under the same strain rate, when the cement content decreased, there was a higher damage degree of specimens.
\end{abstract}

\section{Introduction}

Filling mining method has the advantages of high recovery rate, high safety, and low pollution degree, which has been widely used in underground mines at home and abroad [1-3]. The full tailings cemented backfilling is a commonly used filling material in metal mine. According to the characteristics of the mining process, it is vital to grasp the dynamic mechanical characteristics of the cemented backfilling for filling mining technology [4]. Many scholars have conducted relevant research studies on the dynamic and static mechanical properties of full tailings cemented backfilling. Xue [5] carried out quasistatic uniaxial compression and splitting tests on the full tailings cemented backfilling of Huangmeiling Mine and studied the quasistatic mechanical properties of the full tailings cemented backfilling. Dong [6] conducted an onsite blasting vibration test on the backfill body and studied the damage law of the backfill under blasting vibration. Zhixiang et al. [7] analyzed the deformation and damage characteristics of different proportions of backfills and established the damage of different filling backfills. Structural equations were studied to investigate the deformation, damage, and energy release of different filling ratios. However, there are certain limitations in these studies. For instance, the cement-sand ratio of the backfills was relatively single, and the dynamic load was small in the literature [4-6]. The literature [7] could not reflect mechanical properties of the full tailings cemented backfilling at high strain rates. In this paper, the relationship between the dynamic stress-strain rate of the material was studied by using the split-Hopkinson pressure bar (SHPB) [8-10]. In order to study the effect of cement-sand ratio on the dynamic mechanical properties of the full tailings cemented backfilling, three sets of full tailings cemented backfilling specimens with different 
cement-sand ratio were prefabricated, and uniaxial impact tests were performed on precast specimens by $\Phi 50 \mathrm{~mm}$ SHPB test system, so as to investigate the dynamic mechanical properties of specimens at high strain rates.

\section{SHPB Test Principle}

The split-Hopkinson pressure bar (SHPB) was developed by Hopkinson [11] and further improved by Kolsky [12] to test the strength of materials at high strain rates from 101 to $104 \mathrm{~s}$. Li et al. [13] developed a cone-shaped striker which could produce a well-repeatable and slow-rising half-sine wave to reduce high frequency oscillations, minimize the dispersion effect, and overcome the premature failure for brittle materials. Due to its easy operation and relatively accurate results, it was suggested as a standard testing method for dynamic properties of rock materials including dynamic compressive and tensile strengths, as well as mode I fracture toughness by the International Society for Rock Mechanics [14].

Figure 1 is a schematic diagram of the SHPB compression test principle. The test system consists of a launcher, a punch, an entrance rod (density: $7.810 \mathrm{~g} / \mathrm{cm}^{3}$, elastic wave velocity: $5410 \mathrm{~m} / \mathrm{s}$, and wave impedance: $4.23 \times 107 \mathrm{~kg} \cdot \mathrm{m}^{-2} \cdot \mathrm{s}^{-1}$ ), and transmissive rod, etc. The test sample was sandwiched between the incident rod and the transmissive rod. The punch hit the incident rod under the action of high pressure, and a stress pulse $\left(\sigma_{\mathrm{I}}(t)\right)$ was generated at the end of the incident rod. Under the condition of onedimensional stress propagation, the stress pulse, namely, the elastic stress incident wave, propagated forward at the wave velocity $C_{0}$ in the entrance rod. The reflection stress pulse $\left(\sigma_{\mathrm{R}}(t)\right)$ and a transmission stress pulse $\left(\sigma_{\mathrm{T}}(t)\right)$ were generated in the entrance rod and the transmission rod after contacting the sample. Besides, the incident strain $\left(\varepsilon_{\mathrm{I}}(t)\right)$ and the reflection strain $\left(\varepsilon_{\mathrm{R}}(t)\right)$ were generated at the end of the specimen, and the transmission strain $\left(\varepsilon_{\mathrm{T}}(t)\right)$ was produced by the transmitted rod simultaneously. The dynamic stress $\left(\sigma_{\mathrm{s}}(t)\right)$, strain rate $\left(\dot{\varepsilon}_{\mathrm{s}}(t)\right)$, and strain $\left(\varepsilon_{\mathrm{s}}(t)\right)$ of the specimen were related to each strain as shown in the following equations:

$$
\begin{aligned}
& \sigma_{\mathrm{s}}(t)=\frac{A E}{2 A_{\mathrm{s}}}\left[\varepsilon_{\mathrm{I}}(t)+\varepsilon_{\mathrm{R}}(t)+\varepsilon_{\mathrm{T}}(t)\right], \\
& \dot{\varepsilon}_{\mathrm{s}}(t)=\frac{C_{0}}{l_{\mathrm{s}}}\left[\varepsilon_{\mathrm{T}}(t)-\varepsilon_{\mathrm{I}}(t)+\varepsilon_{\mathrm{R}}(t)\right], \\
& \varepsilon_{\mathrm{s}}(t)=\frac{C_{0}}{l_{\mathrm{s}}} \int_{0}^{t}\left[\varepsilon_{\mathrm{T}}(t)-\varepsilon_{\mathrm{I}}(t)+\varepsilon_{\mathrm{R}}(t)\right] d t,
\end{aligned}
$$

where $A$ is the cross-sectional area of the incident rod; $A_{\mathrm{s}}$ is the cross-sectional area of the specimen; $E$ is the elastic modulus of the plunger; and $l_{s}$ is the thickness of the specimen.

According to the one-dimensional stress assumption, when the sample stress reaches the equilibrium, Equation (4) is obtained as

$$
\varepsilon_{\mathrm{T}}(t)=\varepsilon_{\mathrm{I}}(t)+\varepsilon_{\mathrm{R}}(t) .
$$

Subsequently, Equation (1) (3) can be simplified as

$$
\begin{aligned}
\sigma_{\mathrm{s}}(t) & =\frac{A E}{A_{\mathrm{s}}} \mathcal{E}_{\mathrm{T}}(t), \\
\dot{\varepsilon}(t) & =-2 \frac{C_{0}}{l_{\mathrm{s}}} \varepsilon_{\mathrm{R}}(t), \\
\varepsilon & (t)=-2 \frac{C_{0}}{l_{\mathrm{s}}} \int_{0}^{t} \varepsilon_{\mathrm{R}}(t) d t .
\end{aligned}
$$

\section{Test Materials and Equipment}

Full tailings of an iron ore mine in Hebei Province was taken as the aggregate of samples. The proportion of particles below $0.075 \mathrm{~mm}$ in tailings was $69.1 \%$, and the median diameter $d_{50}(\mathrm{~mm})$ was 0.049 . 525\# Portland cement was used as a gelling agent whose mass concentration was $72 \%$. The cement-sand ratio was $1: 4,1: 6$, and $1: 8$, respectively. Figure 2 shows a sketch of the specimen. The basic physical and mechanics parameters of the full tailings cement block are shown in Table 1.

\section{Mechanical Test Results and Analysis}

In rock dynamics, the growth factor of dynamic strength $K$ and the dynamic-static strain ratio $P$ are often used to quantify the strength variation of the specimen under dynamic and static load conditions [15]. Expressions of $K$ and $P$ are given by Equations (6) and (7) as follows. These two indicators were also used to assist the analysis in this test result:

$$
\begin{gathered}
K=\frac{\sigma_{\mathrm{s}}}{\sigma}, \\
P=\frac{\varepsilon_{\mathrm{s}}}{\varepsilon},
\end{gathered}
$$

where $K$ is the growth factor of dynamic strength; $P$ is the dynamic-static strain ratio; $\sigma_{\mathrm{s}}$ is the dynamic compressive strength of the sample; $\sigma$ is the static compressive strength of the sample; and $\varepsilon_{\mathrm{s}}$ and $\varepsilon$ are the maximum strains of the sample under dynamic load and static load, respectively.

4.1. SHPB Original Waveform. The typical incident wave, reflected wave, and transmitted wave waveform obtained by the test recorder are shown in Figure 3. From the original waveform diagram, it can be seen basically that the amplitude of the incident wave and the reflected wave is approximately equal with opposite directions, while the amplitude of the transmitted wave is relatively small. Wave impedance theory can explain this phenomenon clearly [16]. When an elastic wave was incident on a low-wave impedance material from a high-wave impedance material, the reflected wave and the incident wave were different in sign, and the transmitted wave had a smaller magnitude of stress amplitude than that of the incident wave. Namely, the stress 


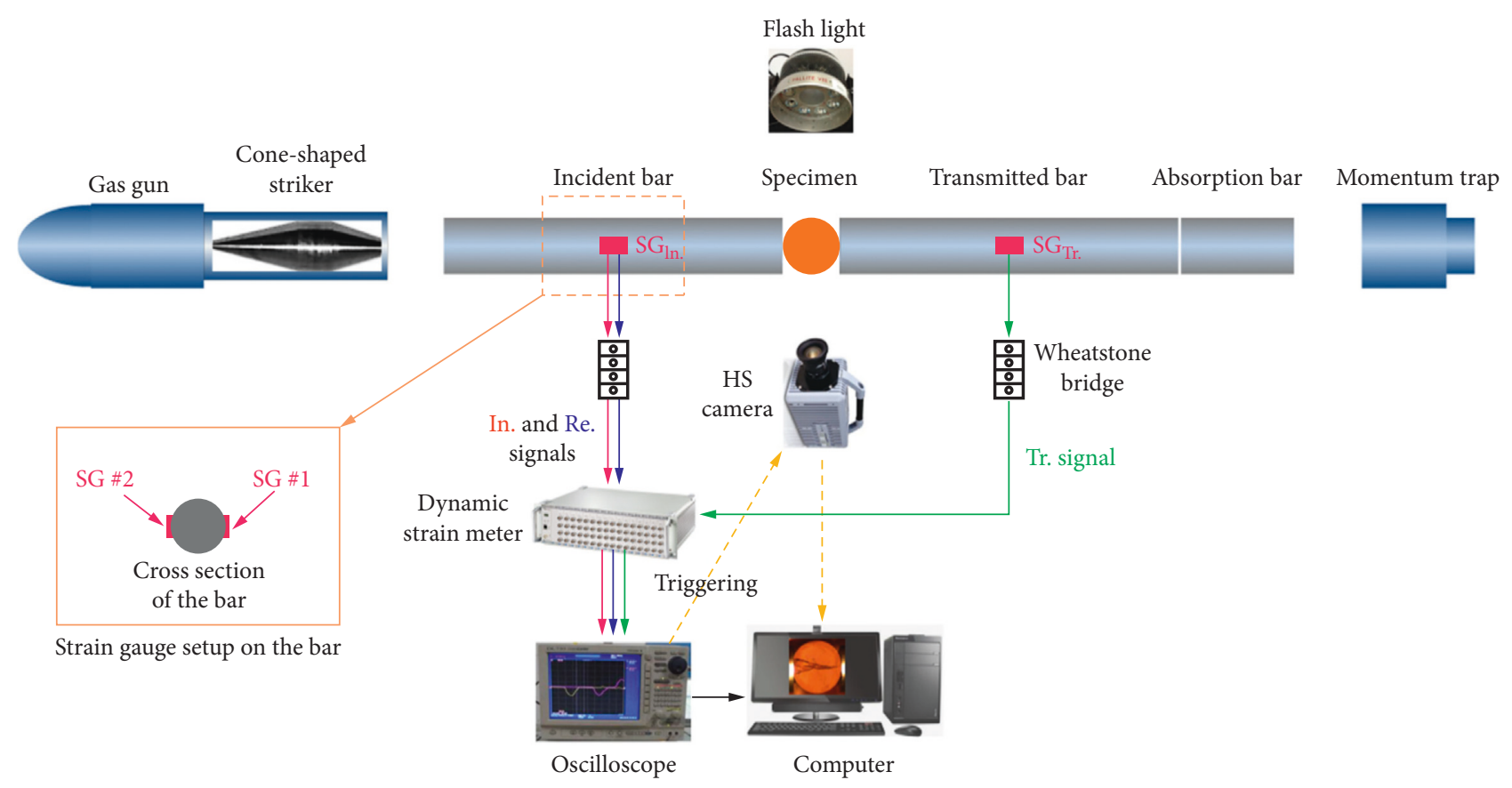

FIGURE 1: Schematic illustration of the modified SHPB setup (In: incident; Re: reflected; Tr: transmitted; SG: strain gauge).

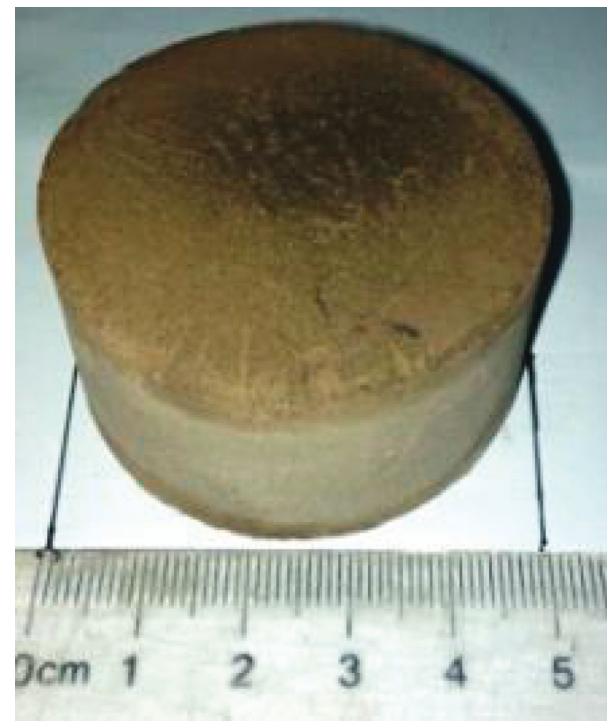

Figure 2: Schematic diagram of the specimen.

TABle 1: Physical and mechanics parameters of specimen.

\begin{tabular}{|c|c|c|c|c|c|c|c|c|c|}
\hline Group & $\begin{array}{l}\text { Cement- } \\
\text { sand } \\
\text { ratio }\end{array}$ & $\begin{array}{l}\text { Size } \\
(\mathrm{mm})\end{array}$ & $\begin{array}{l}\text { Density } \\
(\%)\end{array}$ & $\begin{array}{c}\text { Average density } \\
\left(\mathrm{kg} \cdot \mathrm{m}^{-3}\right)\end{array}$ & $\begin{array}{c}\text { Elasticity moduli } \\
(\mathrm{MPa})\end{array}$ & $\begin{array}{c}\text { Wave } \\
\text { velocity } \\
\left(\mathrm{m} \cdot \mathrm{s}^{-1}\right)\end{array}$ & $\begin{array}{l}\text { Compressive } \\
\text { strength } \\
(\mathrm{MPa})\end{array}$ & $\begin{array}{l}\text { Maximum } \\
\text { strain }\end{array}$ & $\begin{array}{l}\text { Wave impedance } \\
\left(\mathrm{kg} \cdot \mathrm{m}^{-2} \cdot \mathrm{s}^{-1}\right)\end{array}$ \\
\hline$\overline{\mathrm{A}}$ & $1: 4$ & $\Phi 50 \times 25$ & 72 & 1553 & 203.46 & 997 & 2.73 & 0.055 & $1.55 \times 10^{6}$ \\
\hline B & $1: 6$ & $\Phi 50 \times 25$ & 72 & 1592 & 164.25 & 850 & 2.14 & 0.034 & $1.35 \times 10^{6}$ \\
\hline $\mathrm{C}$ & $1: 8$ & $\Phi 50 \times 25$ & 72 & 1627 & 139.63 & 783 & 1.38 & 0.009 & $1.27 \times 10^{6}$ \\
\hline
\end{tabular}

wave was transmitted from the hard material to the soft material. The incident wave impedance of the rod $\left(4.23 \times 107 \mathrm{~kg} \cdot \mathrm{m}^{-2} \cdot \mathrm{s}^{-1}\right)$ was much larger than that of the full tail cement specimen, while the stress amplitude of transmitted wave was much smaller than that of the incident wave. Figure 3 illustrates that full tailings cemented backfilling test specimen has a strong damping effect on the elastic wave propagation. 


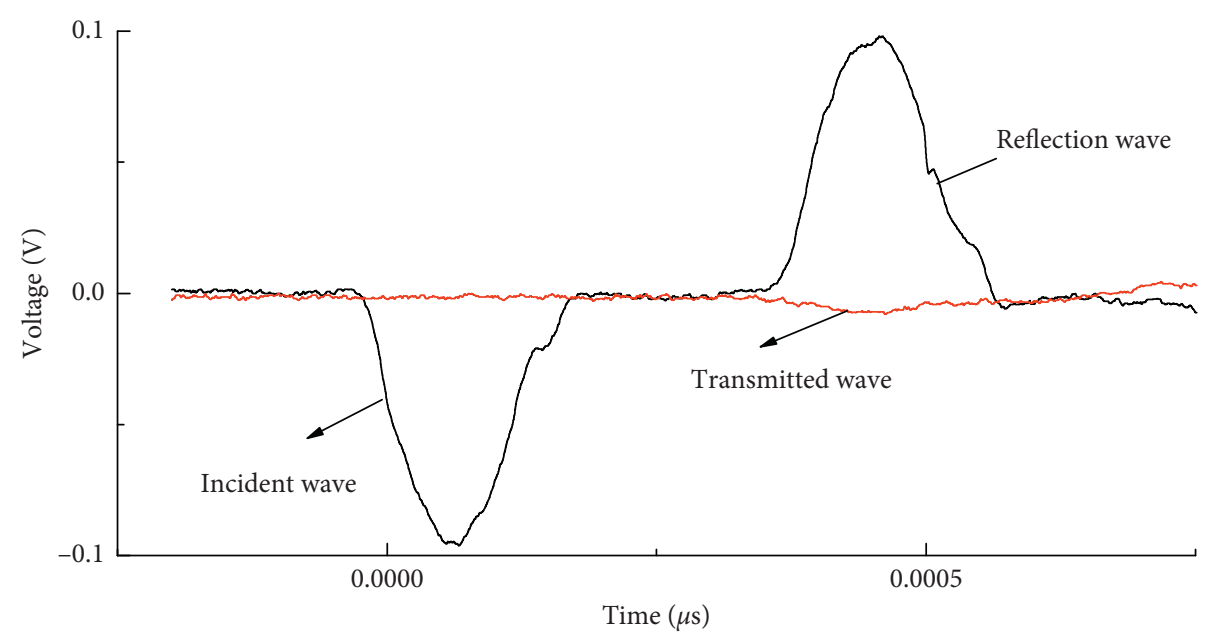

FIgURE 3: The typical waveform figure of SHPB testing.

\subsection{Mechanical Test Results and Analysis}

4.2.1. Test Results. The uniaxial impact test has been divided into 3 groups and conducted for 36 times, which obtained 30 groups of ideal test results. The partial results of mechanical tests are shown in Table 2. Typical stress-strain curves in the tests are shown in Figure 4.

4.2.2. Dynamic Properties of Specimens. The test results in Table 2 were extracted and fitted, as shown in Figures 5-8. The relationship between the dynamic compressive strength and the strain rate of proportioned specimens has a similar pattern. Test results of specimens in group A are analyzed as an example.

(1) The stress-strain curve of specimens was different from general brittle materials $[17,18]$. The stressstrain curve generally had several stress peaks. At a lower strain rate, the specimen presented dynamic strength hardening. Namely, after reaching stress A, a small part of the specimen began to fail and the stress began to decrease slightly. Meanwhile, the other part of the microcracks was gradually compacted and the stress gradually rose again to the true peak value of stress B. After several "damage-compacting" oscillations, the specimen finally failed, as shown in Figure 4(a). At higher strain rates, the specimen showed a rapid softening of the dynamic strength [19]. Namely, under the impact load, when the stress reached the stress peak quickly, most of the specimen began to break with the rapid decrease of the stress. At the same time, compaction process occurred in the other parts, and the stress rose slightly. After several waveform oscillation processes, the sample was damaged finally, as shown in Figure 4(b). From Table 2, it can be seen that all strength-hardened specimens reach peak stress after $40 \mu \mathrm{s}$, and all strength accelerating softening specimens reach peak stress around $18 \mu \mathrm{s}$.
(2) From Table 2, it can be seen that, the dynamic compressive strength increases with the increase of the strain rate in the initial stage. When the strain rate reaches $266 \mathrm{~s}^{-1}$, the dynamic compressive strength $\sigma_{\mathrm{A}}$ reaches the maximum, $\sigma_{\mathrm{A}}$ of $17.27 \mathrm{MPa}$, while with the increasing strain rate, it decreases. The stress-strain rate fitting curve is shown in Figure 5, and the fitting relationship is obtained in the following equation:

$$
\begin{aligned}
\sigma_{\mathrm{A}}= & -2 \times 10^{-8} \dot{\varepsilon}^{4}+9 \times 10^{-6} \dot{\varepsilon}^{3}-0.0017 \dot{\varepsilon}^{2} \\
& +0.196 \dot{\varepsilon}-4.1266
\end{aligned}
$$

(3) Figure 6 illustrates that the growth factor of dynamic strength $K_{\mathrm{A}}$ increases significantly with the increasing strain rate. $K_{\text {Amax }}$ is 6.28 , which means that the dynamic compressive strength is 6.28 times than the static compressive strength, while the general dynamic growth factor of the rock is only 1.2-2.5 or so [20]. The fitting curve of dynamic strength growth factor and strain rate is shown in Figure 6, and the fitting relationship is described in the following equation:

$$
\begin{aligned}
K_{\mathrm{A}}= & -6 \times 10^{-9} \dot{\varepsilon}^{4}+3 \times 10^{-6} \dot{\varepsilon}^{3}-0.0006 \dot{\varepsilon}^{2} \\
& +0.0173 \dot{\varepsilon}-1.5006
\end{aligned}
$$

(4) Figure 7 indicates that as the strain rate increases, the peak strain $\varepsilon_{\mathrm{A}}$ of all specimens has a linear increasing trend with the limit peak strain $\varepsilon_{\mathrm{A}}$ of 0.0274. Comparing Table 1 and Table 2, maximum dynamic strain is less than the maximum quasistatic strain, and the dynamic-static strain ratio $P_{\mathrm{A}}$ increases with the increase of strain rate, $P_{\mathrm{A} \max }=0.5$. Besides, the fitting curve of maximum dynamicstatic strain ratio and strain rate is shown in Figure 8 , and the fitting relationship is described in the following equation: 
TABle 2: Test results of mechanics.

\begin{tabular}{|c|c|c|c|c|c|c|c|}
\hline Number & Ratio & Strain rate $\left(\mathrm{s}^{-1}\right)$ & Peak stress $(\mathrm{MPa})$ & Peak time $(\mu \mathrm{s})$ & Dynamic strength growth factor & Peak strain & $\begin{array}{c}\text { Dynamic and static } \\
\text { strain ratio }\end{array}$ \\
\hline$\overline{\mathrm{A}_{4}}$ & $1: 4$ & 56 & 2.89 & 55.00 & 1.05 & 0.0067 & 0.12 \\
\hline $\mathrm{A}_{5}$ & $1: 4$ & 79 & 5.16 & 19.00 & 1.88 & 0.0101 & 0.18 \\
\hline $\mathrm{A}_{6}$ & $1: 4$ & 103 & 4.57 & 19.00 & 1.66 & 0.0122 & 0.22 \\
\hline $\mathrm{A}_{7}$ & $1: 4$ & 118 & 6.73 & 20.00 & 2.45 & 0.0136 & 0.25 \\
\hline $\mathrm{A}_{8}$ & $1: 4$ & 129 & 7.44 & 47.00 & 2.71 & 0.0146 & 0.26 \\
\hline $\mathrm{A}_{9}$ & $1: 4$ & 141 & 10.11 & 20.00 & 3.68 & 0.0153 & 0.28 \\
\hline $\mathrm{A}_{10}$ & $1: 4$ & 203 & 12.78 & 17.00 & 4.65 & 0.0183 & 0.33 \\
\hline $\mathrm{A}_{11}$ & $1: 4$ & 221 & 14.50 & 18.00 & 5.27 & 0.0194 & 0.35 \\
\hline $\mathrm{A}_{12}$ & $1: 4$ & 247 & 15.92 & 19.00 & 5.79 & 0.0219 & 0.40 \\
\hline $\mathrm{A}_{13}$ & $1: 4$ & 266 & 17.27 & 18.00 & 6.28 & 0.0236 & 0.43 \\
\hline $\mathrm{A}_{14}$ & $1: 4$ & 305 & 14.19 & 19.00 & 5.16 & 0.0274 & 0.50 \\
\hline $\mathrm{B}_{3}$ & $1: 6$ & 50 & 2.48 & 53.00 & 1.16 & 0.0043 & 0.12 \\
\hline $\mathrm{B}_{4}$ & $1: 6$ & 56 & 3.08 & 53.00 & 1.44 & 0.0065 & 0.19 \\
\hline $\mathrm{B}_{5}$ & $1: 6$ & 80 & 6.33 & 44.00 & 2.96 & 0.0089 & 0.25 \\
\hline $\mathrm{B}_{6}$ & $1: 6$ & 105 & 6.72 & 41.00 & 3.14 & 0.0099 & 0.28 \\
\hline $\mathrm{B}_{7}$ & $1: 6$ & 112 & 8.95 & 45.00 & 4.18 & 0.0103 & 0.29 \\
\hline $\mathrm{B}_{8}$ & $1: 6$ & 123 & 11.25 & 43.00 & 5.26 & 0.0110 & 0.32 \\
\hline $\mathrm{B}_{9}$ & $1: 6$ & 127 & 11.41 & 17.00 & 5.33 & 0.0115 & 0.33 \\
\hline $\mathrm{B}_{10}$ & $1: 6$ & 167 & 12.02 & 19.00 & 5.62 & 0.0145 & 0.42 \\
\hline $\mathrm{B}_{11}$ & $1: 6$ & 168 & 12.42 & 18.00 & 5.80 & 0.0150 & 0.43 \\
\hline $\mathrm{B}_{12}$ & $1: 6$ & 185 & 10.91 & 18.00 & 4.66 & 0.0154 & 0.44 \\
\hline$\overline{C_{3}}$ & $1: 8$ & 43 & 2.03 & 16.00 & 1.47 & 0.0009 & 0.06 \\
\hline $\mathrm{C}_{4}$ & $1: 8$ & 56 & 3.73 & 45.00 & 2.70 & 0.0015 & 0.10 \\
\hline $\mathrm{C}_{5}$ & $1: 8$ & 68 & 5.38 & 50.00 & 3.90 & 0.0023 & 0.15 \\
\hline $\mathrm{C}_{6}$ & $1: 8$ & 75 & 6.88 & 20.00 & 4.99 & 0.0034 & 0.23 \\
\hline $\mathrm{C}_{7}$ & $1: 8$ & 82 & 7.84 & 18.00 & 5.68 & 0.0043 & 0.29 \\
\hline $\mathrm{C}_{8}$ & $1: 8$ & 91 & 8.87 & 22.00 & 6.43 & 0.0047 & 0.31 \\
\hline $\mathrm{C}_{9}$ & $1: 8$ & 95 & 7.22 & 18.00 & 5.23 & 0.0049 & 0.33 \\
\hline $\mathrm{C}_{10}$ & $1: 8$ & 102 & 9.54 & 19.00 & 6.91 & 0.0054 & 0.36 \\
\hline $\mathrm{C}_{11}$ & $1: 8$ & 120 & 8.73 & 17.00 & 6.33 & 0.0068 & 0.45 \\
\hline
\end{tabular}
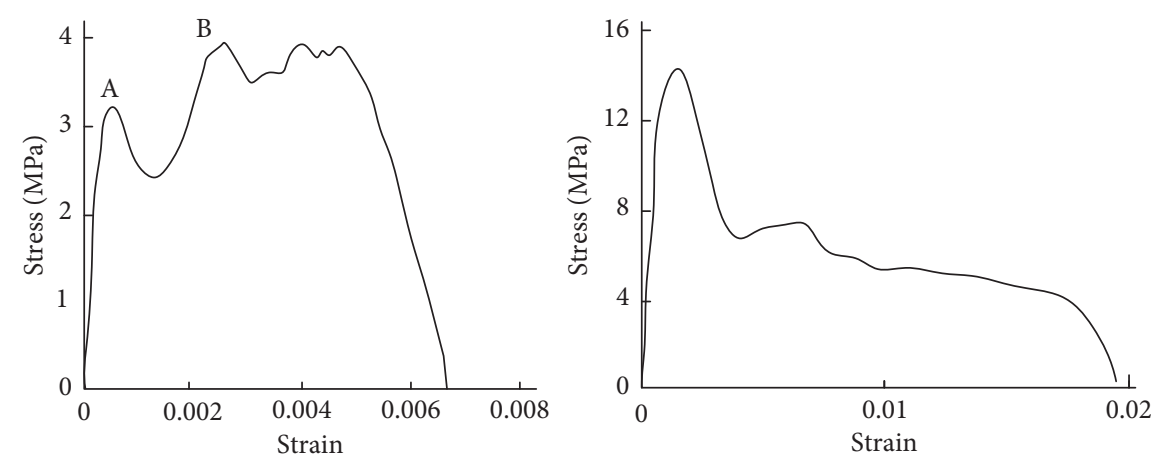

FIgURE 4: Typical stress-strain curve.

$$
\begin{aligned}
& \varepsilon_{\mathrm{A}}=7 \times 10^{-5} \dot{\varepsilon}+0.004, \\
& P_{\mathrm{A}}=0.0013 \dot{\varepsilon}+0.0744
\end{aligned}
$$

\subsubsection{Effect of Cement-Sand Ratio on Dynamic Mechanical Properties of Specimen}

(1) Figure 5 indicates that the greater the cement content (cement-sand ratio), the greater the ultimate dynamic compressive strength $\sigma_{\max }$ of the specimen and the greater the strain rate corresponding to $\sigma_{\max }$; at the same strain rate, the dynamic compressive strength of the specimen decreases with increasing cement content. Figure 6 shows that the larger the cement content, the larger the growth factor of limit dynamic strength $K_{\max }$ of the specimen and the larger the strain rate corresponding to $K_{\max }$; at the same strain rate, the $K$ value of the specimen decreases with the increasing cement content.

(2) Figure 7 shows that the larger the cement content, the larger the limit dynamic strain $\varepsilon_{\max }$ of the specimen 


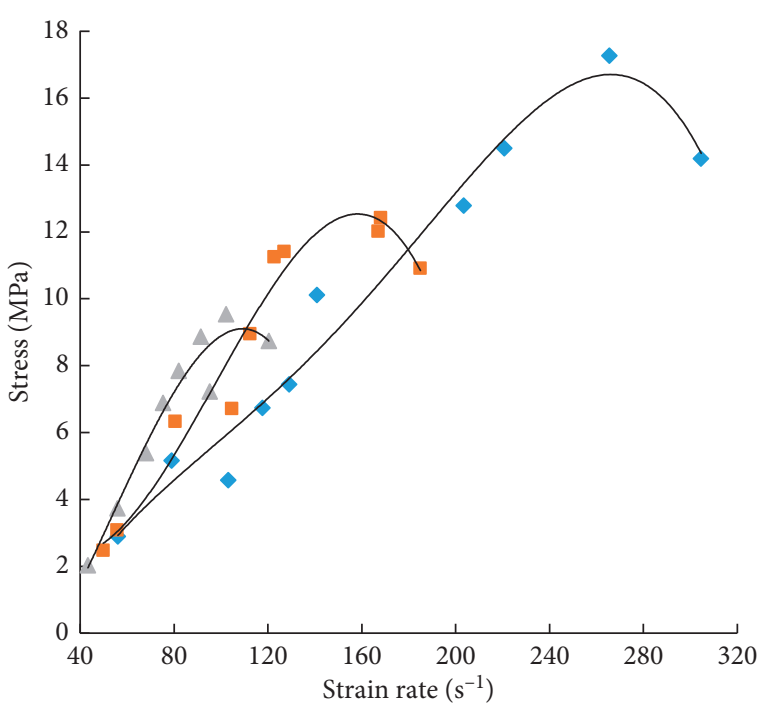

- Cement-sand ratio $1: 4$

- Cement-sand ratio 1:6

$\triangle$ Cement-sand ratio 1:8

Figure 5: The stress and strain rate curve.

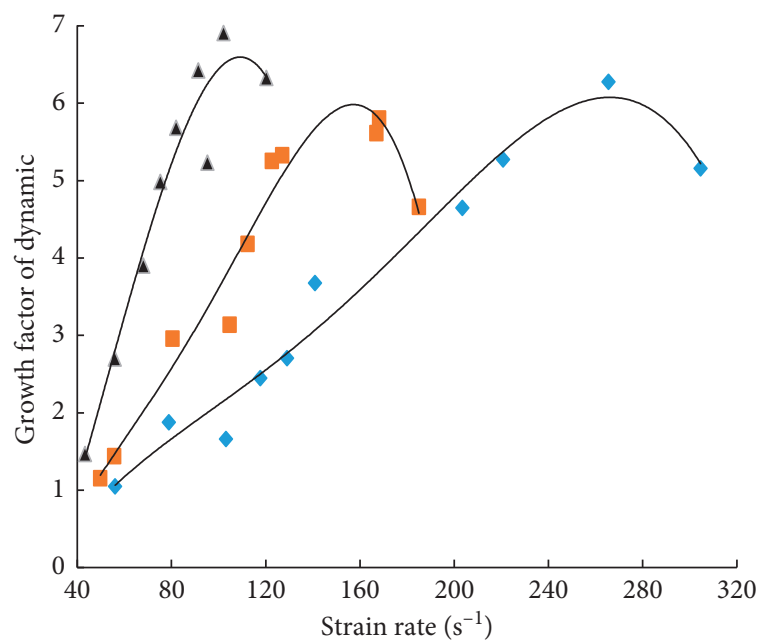

- Cement-sand ratio 1:4

- Cement-sand ratio 1:6

A Cement-sand ratio $1: 8$

Figure 6: The stress and strain rate curve.

and the greater the strain rate corresponding to $\varepsilon_{\max }$; at the same strain rate, the peak strain $\varepsilon$ of the specimen increases as the cement content increases. Figure 8 shows that the greater the cement content, the smaller the maximum dynamic and static strain ratio $P_{\max }$ of the specimen; at the same strain rate, the dynamic and static strain ratio $P$ of the specimen decreases as the cement content increases.

(3) As shown in Figure 9, as a whole, the failure mode of the test block is crush damage, which is similar to the damage form of low-strength concrete [17]. At the same strain rate, the lesser the cement content, the

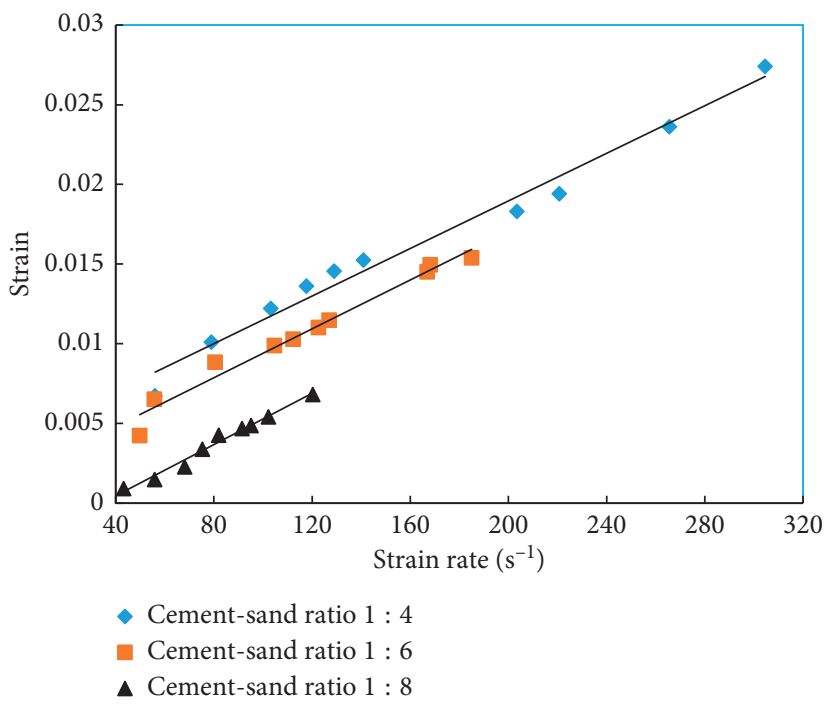

FIgURE 7: The strain and strain rate curve.

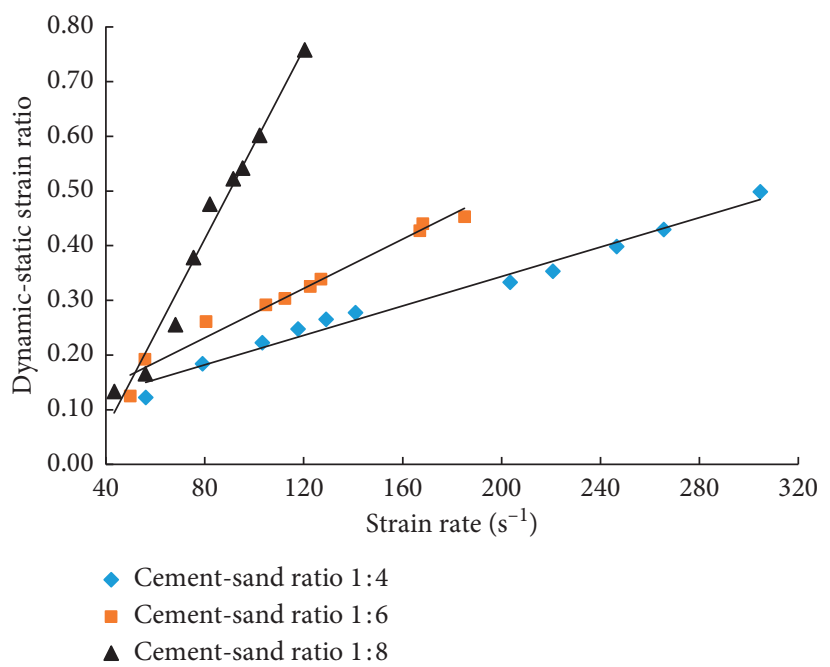

Figure 8: The dynamic and static strain ratio and strain rate curve.

higher the damage degree of the test block. Taking the strain rate of $56 \mathrm{~s}^{-1}$ as an example, when cementsand ratio was $1: 4$, the specimen was situated in a critical failure state, and the specimen presented chapping failure in the axial direction (Figure 9(a)); when the cement-sand ratio was $1: 6$, the number of fragments in specimens relatively increased and a small amount of powder was presented (Figure 9(b)). When the cement-sand ratio was $1: 6$, most of the specimens were completely pressed into powders with few small particles (Figure 9(c)).

\section{Conclusions}

In order to study the effect of cement-sand ratio on the dynamic mechanical properties of the full tailings cemented backfilling, three sets of full tailings cemented backfilling specimens with different cement-sand ratio 


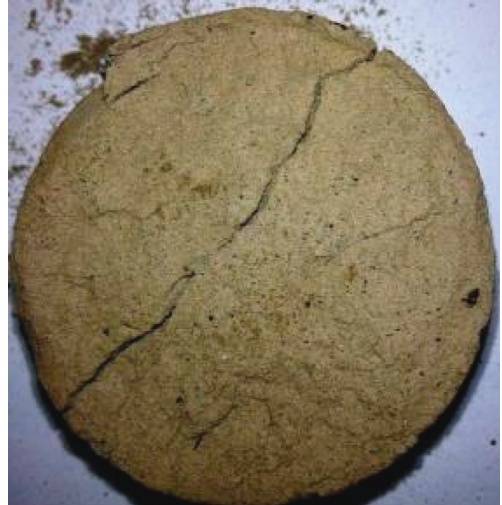

(a)

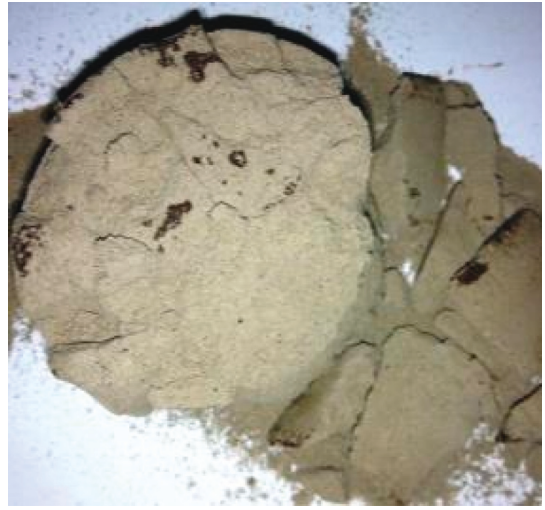

(b)

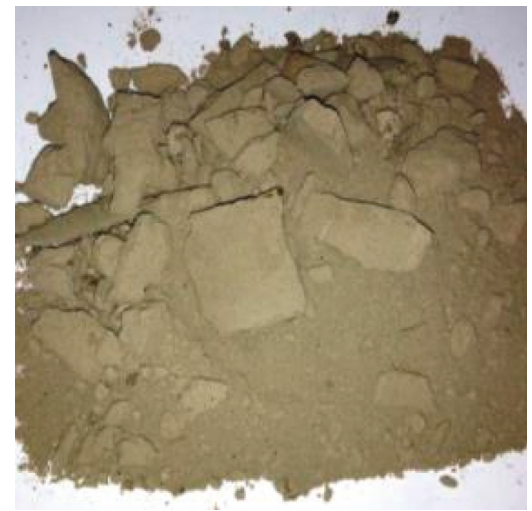

(c)

Figure 9: The failure mode of the specimen when $\dot{\varepsilon}=56 \mathrm{~s}^{-1}$. (a) Cement-sand ratio $1: 4$. (b) Cement-sand ratio $1: 6$. (c) Cementsand ratio $1: 8$.

were prefabricated. Uniaxial impact tests were performed on precast specimens by the $\Phi 50 \mathrm{~mm}$ SHPB test system. Conclusions are obtained as follows:

(1) According to the original waveform diagram of SHPB, the full tailings cemented backfilling had strong reflection and damping effects on elastic wave propagation.

(2) Stress-strain curves of the specimen were divided into two types: hardening and softening. At lower strain rates, specimens presented strength hardening; at higher strain rates, the specimens showed rapid-softening strength. The strengthhardened specimen reached its peak stress after $40 \mu \mathrm{s}$, and the strength-accelerating softening specimen reached peak stress at about $18 \mu \mathrm{s}$; The dynamic compressive strength, growth factor of dynamic strength, peak strain, and dynamic-static strain ratio of the specimen increased with the increasing strain rate.

(3) The higher the cement content (cement-sand ratio), the greater the ultimate dynamic compressive strength, the limit dynamic strength growth factor, and the ultimate peak strain of the specimen; at the same strain rate, the dynamic compressive strength, growth factor of dynamic strength, and dynamicstrain ratio of the specimen decreased with increasing cement content. The failure mode of the specimen was crush damage. Under the same strain rate, lesser the cement content, the higher the damage degree of the specimen.

\section{Data Availability}

The experimental data used to support the findings of this study are included within the article.

\section{Conflicts of Interest}

The authors declare that they have no conflicts of interest.

\section{Acknowledgments}

This study was supported by the National Natural Science Foundation of China (Grant nos. 51404305 and 51504286).

\section{References}

[1] F. Yu-lu, W. Yang, Z. Guo-hui et al., "Surround rock stability of mined- out area under blast loading metal mine pillar robbing," Explosion and Shock Waves, vol. 33, no. 4, pp. 344-350, 2013.

[2] Q. Zhang, W. Yang, and X. Wang, "Experiment with filling the stope area with the wet paste-like fly ash material," Journal of Safety and Environment, vol. 14, no. 5, pp. 70-72, 2014.

[3] G. Huang, S. J. Cai, Y. D. Zhang, and D. Wu, "Experimental and modeling study on the strength of tailings backfill in underground mine," Applied Mechanics and Materials, vol. 522-524, pp. 1390-1393, 2014.

[4] M. Fall, J. C. Célestin, M. Pokharel, and M. Touré, "A contribution to understanding the effects of curing temperature on the mechanical properties of mine cemented tailings backfill," Engineering Geology, vol. 114, no. 3-4, pp. 397-413, 2010.

[5] X.-L. Xue, A Study of High Density Total Tailings Backfill Technology in Huangmei Phosphorus Mine, Central South University, Changsha, China, 2012.

[6] K.-C. Dong, Research on the Influence and Control Techniques of Blasting Seismic Wave on Backfill, Central South University, Changsha, China, 2010.

[7] L. Zhi-Xiang, Li. Xi-bing, D. Ta-gen, and C. Ping, "On damage model of cemented tailings backfill and its match with rock 
mass," Rock and Soil Mechanics, vol. 27, no. 9, pp. 1442-1446, 2006.

[8] Z. Zhou, X. Li, Z. Ye, and K. Liu, "Obtaining constitutive relationship for rate-dependent rock in SHPB tests," Rock Mechanics and Rock Engineering, vol. 43, no. 6, pp. 697-706, 2010.

[9] H. Meng and Q. M. Li, "Correlation between the accuracy of a SHPB test and the stress uniformity based on numerical experiments," International Journal of Impact Engineering, vol. 28, no. 5, pp. 537-555, 2003.

[10] B. Yang, L. Tang, Y. Liu, Z. Liu, Z. Jiang, and D. Fang, "The deformation measurement and analysis on meso-structure of aluminum foams during SHPB test," Journal of Testing and Evaluation, vol. 42, no. 3, article 20120254, 2014.

[11] B. Hopkinson, "A method of measuring the pressure produced in the detonation of high explosives or by the impact of bullets," Philosophical Transactions of the Royal Society A: Mathematical, Physical and Engineering Sciences, vol. 213, no. 497-508, pp. 437-456, 1914.

[12] H. Kolsky, "An investigation of the mechanical properties of materials at very high rates of loading," Proceedings of the Physical Society. Section B, vol. 62, no. 11, pp. 676-700, 1949.

[13] X. B. Li, T. S. Lok, and J. Zhao, "Dynamic characteristics of granite subjected to intermediate loading rate," Rock Mechanics and Rock Engineering, vol. 38, no. 1, pp. 21-39, 2005.

[14] Z. Zhou, X. Cai, D. Ma, L. Chen, S. Wang, and L. Tan, "Dynamic tensile properties of sandstone subjected to wetting and drying cycles," Construction and Building Materials, vol. 182, pp. 215-232, 2018.

[15] M. Peroni, L. Peroni, and M. Avalle, "High strain-rate compression test on metallic foam using a multiple pulse SHPB apparatus," Journal de Physique IV (Proceedings), vol. 134, pp. 609-616, 2006.

[16] J. Dai, Rock Dynamics and Blasting Theory, Press of Metallurgy Industry, Beijing, China, 2002.

[17] M. R. Mitchell, R. E. Link, S. Wang, M.-H. Zhang, and S. T. Quek, "Effect of specimen size on static strength and dynamic increase factor of high-strength concrete from SHPB test," Journal of Testing and Evaluation, vol. 39, no. 5, article 103370, 2011.

[18] J. Liu, J. Xu, and L. Xiao-cong, "Experimental study on dynamic mechanical properties of amphibolites under impact compressive loading," Chinese Journal of Rock Mechanics and Engineering, vol. 28, no. 10, pp. 2113-2120, 2009.

[19] J. Qu and G. Zou, "A study of the dynamic plane strain fracture toughness of concrete by SHPB," Key Engineering Materials, vol. 385-387, pp. 21-24, 2008.

[20] X. Li, F. Gong, J. Zhao et al., "Test study of impact failure of rock subjected to one-dimensional coupled static and dynamic loads," Chinese Journal of Rock Mechanics and Engineering, vol. 29, no. 2, pp. 251-260, 2010. 


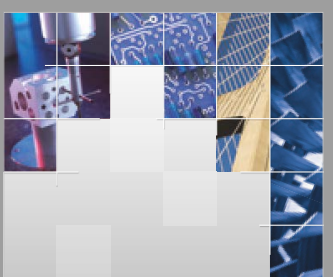

\section{Enfincering}
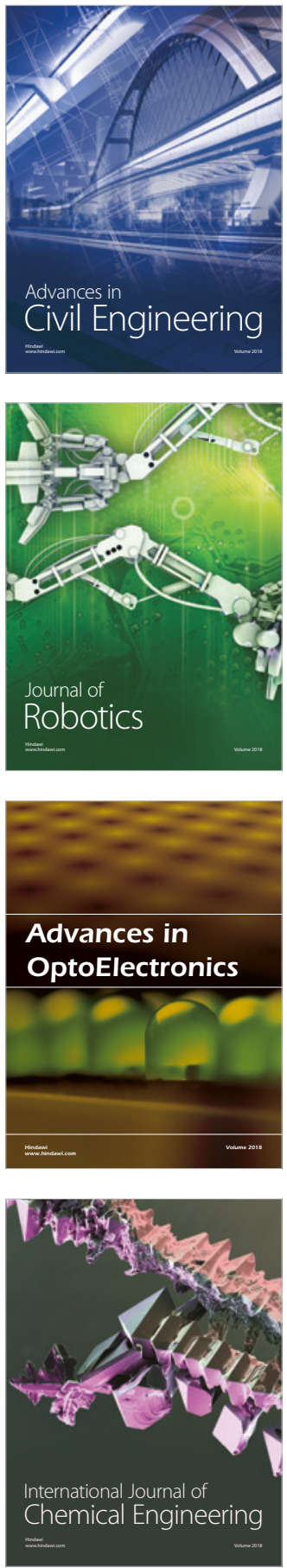

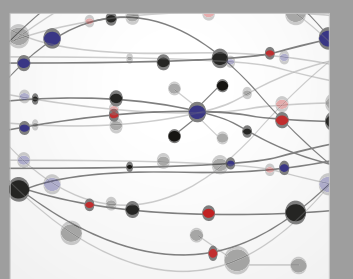

\section{Rotating \\ Machinery}

The Scientific World Journal

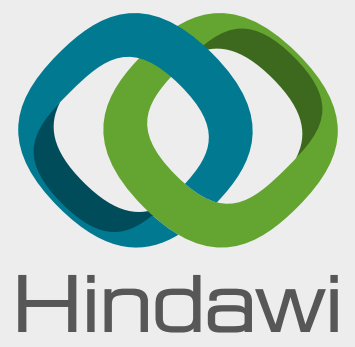

Submit your manuscripts at

www.hindawi.com
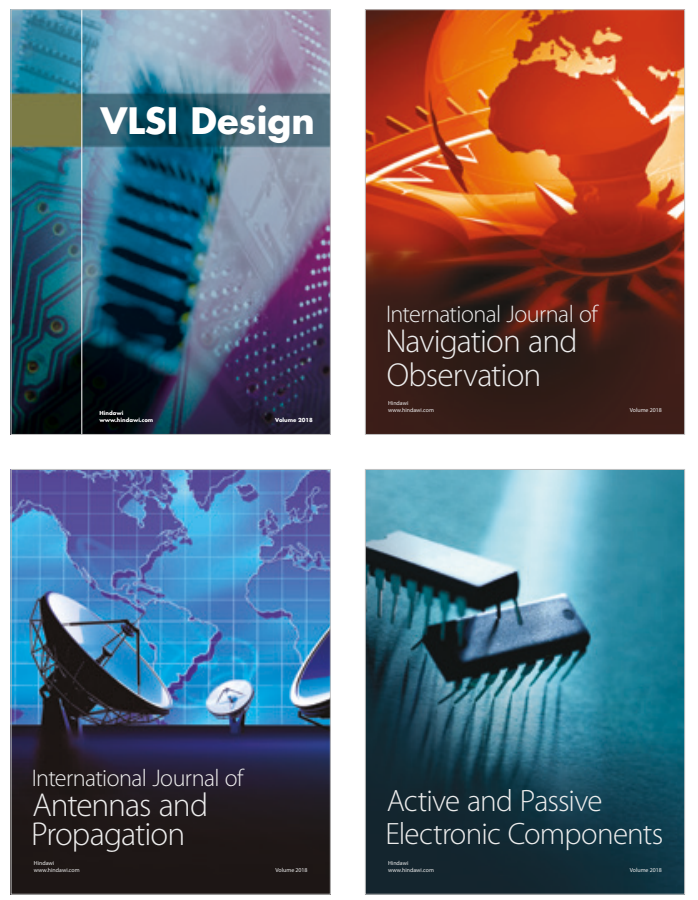
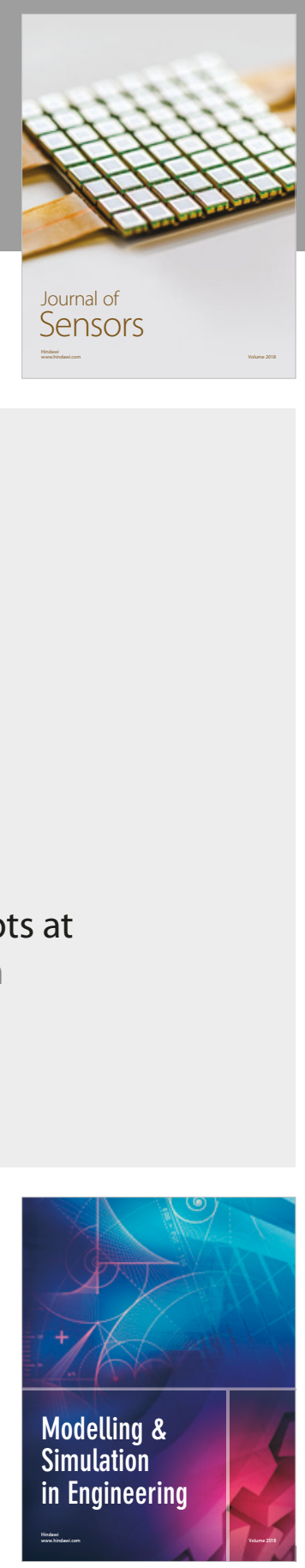

\section{Advances \\ Multimedia}
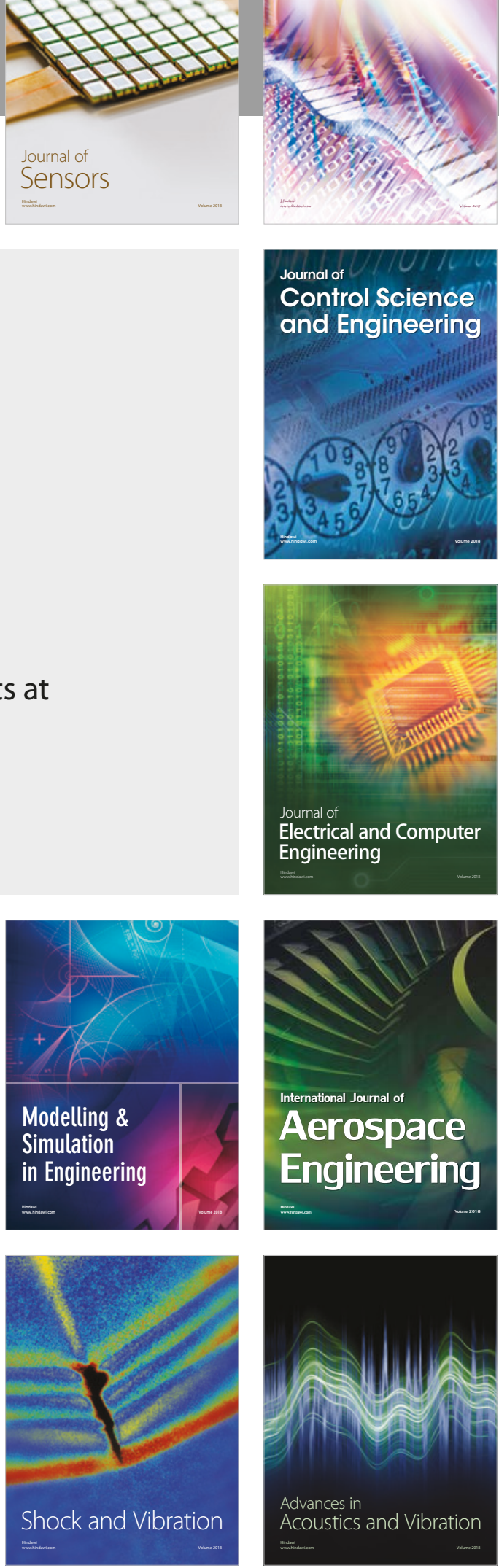